\title{
THE CRITERIAL FREEZING EFFECT AND SPLIT A'-MOVEMENT
}

\author{
MASAKO MAEDA \\ Kyushu University
}

\begin{abstract}
This paper investigates the mechanism of $\mathrm{A}^{\prime}$-movement. Based on Italian data, Rizzi (2006) proposes that Criterial Freezing restricts successive $\mathrm{A}^{\prime}$-movement which satisfies several $\mathrm{A}^{\prime}$-properties, while it does not prohibit the extraction out of the $\mathrm{A}^{\prime}$-moved phrase. However, we will show that some English data express the ban on extraction. We will present split $\mathrm{A}^{\prime}$ movement analysis, which claims that an $\mathrm{A}^{\prime}$-element can split and subphrases move to distinct landing sites in the articulated CP domain. This assumption, together with feature-based relativized minimality (Rizzi (2004)), explains extraction phenomena both in Italian and in English. Further, the notion of the fine periphery is extended to the vP domain and we will give a plausible account for $w h$-movement of associate DPs in there-constructions.*
\end{abstract}

Keywords: Criterial Freezing, the fine structure of the CP periphery, featurebased relativized minimality, there-constructions

\section{Introduction}

It is widely assumed that $\mathrm{A}^{\prime}$-movement contributes to Interface properties. For example, $\mathrm{A}^{\prime}$-elements such as a $w$-phrase or a focus phrase move to the CP domain to induce scope-discourse properties. Rizzi (1996, 1997, 2006) argues that $\mathrm{A}^{\prime}$-movement is triggered by a criterion, which requires a head with some feature to attract the element with the same feature to its Spec. Since A'-movement is triggered by Interface properties, it is natural to suppose that a phrase which has already satisfied an Interface property, i.e. a criterion, cannot move further. This phenomenon is the effect of what Rizzi (2006) calls Criterial Freezing.

* I would like to express my sincere gratitude to Nobuaki Nishioka and two anonymous reviewers for their helpful suggestions and valuable comments. I am also grateful to Stephen Laker for suggesting stylistic improvements. Needless to say, all remaining errors are my own. 
(1) Criterial Freezing

A phrase meeting a criterion is frozen in place.

(Rizzi (2006: 112))

Some evidence from Italian and English is demonstrated in (2), where a wh-phrase which satisfies the Question (Q) Criterion in the embedded $\mathrm{CP}$ domain cannot move to the main $\mathrm{CP}$ domain to satisfy the $\mathrm{Q}$ Criterion again.
a. *[CP [Quanti libri di quale autore $]_{\mathrm{i}} \mathrm{C}^{0}[\mathrm{ti}$
How many books by which author you domandi $\left[\mathrm{CP} t_{\mathrm{i}} \mathrm{C}^{0}\right.$ [siano stati censurati $\left.\left.\left.\left.t_{\mathrm{i}}\right]\right]\right]\right]$ ? wonder have been censored

'How many books by which author do you wonder have been censored?'

(Rizzi (2006: 114))

b. ${ }^{*}\left[\mathrm{CP}[\text { Which book }]_{\mathrm{i}}\right.$ does [Bill wonder $\left[{ }_{\mathrm{CP}} t_{\mathrm{i}} \mathrm{C}^{0}\right.$ [she read $\left.\left.\left.\left.t_{\mathrm{i}}\right]\right]\right]\right]$ ?

(Rizzi (2006: 112))

When a criterion is satisfied between an attracting head and the head of a moved phrase, a phrase embedded in the phrase which has satisfied a criterion does not obey Criterial Freezing, and can be extracted further. For instance, in contrast with (2a), (3) is marginally acceptable, where the subpart of the phrase which has satisfied a criterion is extracted and moves to the matrix CP domain to satisfy the Q Criterion. ${ }^{1}$

(3) ? [CP $[\text { Di quale autore }]_{\mathrm{j}} \mathrm{C}^{0}\left[\right.$ ti domandi $\left[\mathrm{CP} \text { [quanti libri } t_{\mathrm{j}}\right]_{\mathrm{i}} \mathrm{C}^{0}$ [siano stati censurati $\left.t_{\mathrm{i}}\right]$ ]]]?

'By which author do you wonder how many books have been censored?'

(Rizzi (2006: 114))

Next, consider (4), where one phrase contains the relative pronoun del quale 'by whom' and the wh-phrase quanti libri 'how many books.' In this case, the phrase cannot pass through the most deeply embedded CP to the higher CP, satisfying the Wh Criterion in the most deeply embedded clause

${ }^{1}$ It is impossible to split in the opposite order, that is, to extract the most deeply embedded phrase di quale autore 'by which author' to the embedded CP system, and then to move the remnant of the complex phrase to the main CP system. This might be caused by the restriction on remnant movement.

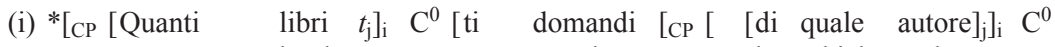 How many books you wonder by which author [siano stati censurati $\left.t_{\mathrm{i}}\right]$ ]]]?
have been censored
'How many books do you wonder by which author have been censored?'

(Rizzi (2006: 114)) 
and then the Relative (Rel) Criterion in the higher clause as in (4a). However, the sentence becomes grammatical if the phrase splits as in (4b), and the subphrase moves to the higher clause.
a. *[Gianni, [CP [quanti
libri
del quale $]_{i} \mathrm{C}^{0}[\mathrm{mi}$
Gianni how many
books
by whom I
domando [ $\mathrm{CP}_{\mathrm{i}} \mathrm{C}^{0}$ [siano stati censurati $\left.\left.\left.\left.t_{\mathrm{i}}\right]\right]\right]\right]$ ]. wonder have been censored

'Gianni, how many books by whom I wonder have been censored.'

b. [Gianni, [CP [del quale $]_{\mathrm{j}} \mathrm{C}^{0}\left[\mathrm{mi}\right.$ domando $\left[\mathrm{CP} \text { [quanti libri } t_{\mathrm{j}}\right]_{\mathrm{i}}$ $\mathrm{C}^{0}$ [siano stati censurati $\left.\left.\left.\left.t_{\mathrm{i}}\right]\right]\right]\right]$.

'Gianni, by whom I wonder how many books have been censored.'

(Rizzi (2006: 116))

Although the notion of Criterial Freezing is quite enlightening in that it explains not only the ban on $\mathrm{A}^{\prime}$-movement which satisfies several criteria, but also the absence of the Freezing effect on sub-extraction from a phrase which satisfies a criterion, it is unclear what mechanism allows the phrase to split. More crucially, the analysis suffers from poor empirical coverage; it may explain Italian data, but it cannot simply be extended to English data. For instance, contrary to the Italian data in (3), English disallows whmovement out of the wh-phrase.

(5) *By which author do you wonder how many books have been censored?

(6) a.?? Who do you wonder which picture of Mary bought?

b.?? Who do you wonder which picture of is on sale?

(Lasnik and Saito (1992: 102))

Similarly, according to several informants, the English counterpart of (4b) is unacceptable, where a relative pronoun is extracted from the wh-moved phrase.

(7)?*The man by whom I wonder how many books have been censored called you last night.

Furthermore, the informants disallow the examples in (8), where a focus phrase moves out of the wh-moved element.

(8) a. *Only children did Lee wonder how many pictures of her mother likes.

b.??Of only children did Lee wonder how many pictures her mother likes.

Now note that not all sub-extractions from the phrases which have satisfied a criterion are unacceptable. Although Lasnik and Saito (1992) and 
Rochemont and Culicover (1990) argue that topicalization from a topic phrase is marginal as in (9) and (10), its acceptability improves when the preposition is pied-piped as in (11).

(9)?? Vowel harmony, I think that articles about, you should read.

(Lasnik and Saito (1992: 101))

(10)?? John, I think that pictures of, Mary likes.

(Rochemont and Culicover (1990: 10))

(11) a. ?About vowel harmony, I think that articles, you should read.

b. ?Of John, I think that pictures, Mary likes.

Further, speakers who reject example (9) accept it if the focal intonation is assigned to vowel harmony. This suggests that focalization from a topic phrase is acceptable.

(12) VOWEL HARMONY, I think that articles of, you should read. Finally, a wh-phrase is successfully extracted from a focus phrase. This contrasts with (8), which shows that a focus phrase cannot escape from the wh-phrase.

(13) a. Of whom did Lee say that only to mothers will she talk?

b. Of whom did Robin say only with children can he communicate?

Summarizing, we get the following results in English. The ungrammaticality of $(14 \mathrm{a}-\mathrm{c})$ is inconsistent with Rizzi's observation in Italian.
a. ${ }^{*}\left[\mathrm{CP}[\mathrm{wh}]_{\mathrm{j}} \mathrm{C}^{0} \ldots\right.$
$\left[\mathrm{CP}\left[w h t_{\mathrm{j}}\right]_{\mathrm{i}} \mathrm{C}^{0}\right.$
$\left.\left[\begin{array}{lll}\ldots & t_{\mathrm{i}} & \ldots\end{array}\right]\right]$
b. ${ }^{*}\left[\mathrm{CP}[\mathrm{rel}]_{\mathrm{j}} \mathrm{C}^{0} \ldots\right.$
$\left[\mathrm{CP}\left[w h t_{\mathrm{j}}\right]_{\mathrm{i}} \mathrm{C}^{0}\right.$
$\left.\left.\left[\ldots t_{\mathrm{i}} \ldots\right]\right]\right]$
c. ${ }^{*}\left[{ }_{\mathrm{CP}}[\text { focus }]_{\mathrm{j}} \mathrm{C}^{0} \ldots{ }_{\mathrm{CP}}\left[\mathrm{wh} t_{\mathrm{j}}\right]_{\mathrm{i}} \mathrm{C}^{0}\right.$
$\left.\left.\left[\ldots t_{\mathrm{i}} \ldots\right]\right]\right]$
d. ?[CP [topic $]_{\mathrm{j}} \mathrm{C}^{0} \ldots \quad\left[\text { [сP [topic } t_{\mathrm{j}}\right]_{\mathrm{i}} \mathrm{C}^{0}$
$\left.\left.\left[\ldots t_{\mathrm{i}} \ldots\right]\right]\right]$
e. $\quad\left[\text { CP }[\text { focus }]_{\mathrm{j}} \mathrm{C}^{0} \ldots{ }_{\text {CP }} \text { [topic } t_{\mathrm{j}}\right]_{\mathrm{i}} \mathrm{C}^{0}$
$\left.\left.\left[\ldots t_{\mathrm{i}} \ldots.\right]\right]\right]$
f. $\left[\mathrm{CP}[\mathrm{wh}]_{\mathrm{j}} \mathrm{C}^{0} \ldots\right.$
[CP [focus $\left.t_{\mathrm{j}}\right]_{\mathrm{i}} \mathrm{C}^{0}$
$\left.\left[\begin{array}{llll}\ldots & t_{\mathrm{i}} & \ldots\end{array}\right]\right]$

The aim of this paper is to explain such complex extraction phenomena in English data as well as Italian data, refining Rizzi's proposal. The notion of criterion depends on the idea that $\mathrm{A}^{\prime}$-movement is triggered by some feature of the attracting head. This, in accordance with the split CP system proposed by Rizzi (1997), leads to the expectation that when one phrase contains two distinct features, the phrase splits and the subparts move to distinct landing sites in the $\mathrm{CP}$ periphery. I will call this movement split $\mathrm{A}^{\prime}$-movement. It will be shown that split $\mathrm{A}^{\prime}$-movement, in connection with Criterial Freezing and relativized minimality, explains various intervention effects concerning $\mathrm{A}^{\prime}$-movement.

This paper is organized as follows. Section two deals with intervention effects between two $\mathrm{A}^{\prime}$-elements based on the fine structure of the $\mathrm{CP}$ 
periphery and feature-based relativized minimality (Rizzi (2004)). Section three turns back to Criterial Freezing phenomena and proposes an alternative theory based on split $\mathrm{A}^{\prime}$-movement. In section four, split $\mathrm{A}^{\prime}$-movement analysis is extended to wh-movement phenomena in there-constructions, introducing the fine structure of the $\mathrm{vP}$ periphery. Section five summarizes the analysis.

\section{Restrictions on $\mathrm{A}^{\prime}$-movement}

In this section we clarify two types of restrictions on $\mathrm{A}^{\prime}$-movement: the relative order of $\mathrm{A}^{\prime}$-elements in the $\mathrm{CP}$ domain and intervention effects concerning $\mathrm{A}^{\prime}$-movement.

\subsection{The Fine Structure of the CP Periphery}

First, let us consider the landing sites of A'-movement. Rizzi (1997) proposes the articulated CP periphery (15).

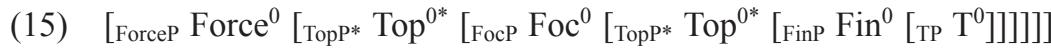
(Rizzi (1997: 297))

Minimally, the CP domain contains ForceP, which encodes the illocutionary force of the clause, and FinP, which expresses (non-)finiteness. The CP system may contain a focus projection FocP and a recursive topic projection TopP when necessary. These heads can be amalgamated into a single head when there is no necessity to split, that is, when several heads do not attract elements to its Spec positions.

Then, Rizzi (1997) and Haegeman (2000) note that different types of $\mathrm{A}^{\prime}$ movement target different positions in the CP periphery. For instance, both in English and in Italian, focalization targets Spec, FocP and topicalization targets Spec, TopP. It is also shown that wh-phrases move to Spec, FocP in main interrogative clauses in English. Further, wh-phrases as well as relative pronouns move to Spec, ForceP in embedded clauses in English (Rizzi (1997: 313), Haegeman (2000: 45)). From this, it follows that the relative order of $\mathrm{A}^{\prime}$-elements in the articulated $\mathrm{CP}$ periphery is fixed. Let us consider the CP domain of an embedded clause in English, which our analysis will be mainly concerned with. Examples in (16) show that multiple topicalization is possible.

(16) a. They told me that liberty, to that man they would never grant.

b. They told me that to that man, liberty they would never grant. (Culicover (1996: 453))

Moreover, as is shown in (17) and (18), a focus phrase is compatible with 
a relative pronoun or a $w h$-phrase, as long as a focus phrase follows a relative pronoun or a wh-phrase. This is because both types of wh-movements target Spec, ForceP and focalization targets Spec, FocP in the embedded CP domain.

(17) a. Terry is the person for whom not even a postage stamp did I remember to buy.

b. *Terry is the person not even a postage stamp did for whom I remember to buy.

c. *Terry is the person not even a postage stamp for whom did I remember to buy.

(Haegeman (2000: 29))

(18) a. Lee wonders what (in the world) in no way would Robin eat.

b. * Lee wonders in no way what (in the world) would Robin eat.

c. *Lee wonders in no way would what (in the world) Robin eat.

Now, let us briefly look at Italian data concerning wh-movement in embedded clauses. Rizzi shows that a relative pronoun must precede a topic phrase as in (19), while a wh-phrase can precede or follow a topic phrase as in (20). Based on this, Rizzi (1997: 289) and Haegeman (2000: 49) suggest that a relative pronoun moves to $\mathrm{Spec}$, ForceP while a wh-phrase moves either to Spec, ForceP or to the lower position in the Foc field. ${ }^{2}$ Here, we simply assume that wh-movements target Spec, ForceP or Spec, FocP.

(19) a. Un uomo a cui, il premio Nobel, lo daranno

A man to whom the prize Nobel give senz'altro.

without doubt

'A man to whom the Nobel Prize, they will give it undoubtedly.'

b. *Un uomo, il premio Nobel, a cui lo daranno senz'altro.

'A man the Nobel Prize, to whom they will give it undoubtedly.'

(Rizzi (1997: 289))

2 Rizzi (1997: 330, fn18) and Haegeman (2000: 49) show that (i) is marginally acceptable, where a wh-phrase co-occurs with a focus phrase in the CP periphery of the embedded clause in Italian. Based on this, they suggest that wh-phrases may reside in some projection in the Foc field, but not in the same projection as FocP which focalization targets.

(i) $\mathrm{Mi}$ chiedo GIANNI chi possa aver osato invitare. Me ask GIANNI who could have dared to invite 'I wonder GIANNI who could have dared to invite.' (Haegeman (2000: 49)) 
(20) a. Mi domand, il premio Nobel, a chi lo potrebbero dare. I wonder the prize Nobel to whom give it 'I wonder, the Nobel Prize, to whom they could give it.'

b. Mi domand a chi, il premio Nobel, lo potrebbero dare.

'I wonder to whom, the Nobel Prize, they could give it.'

(Rizzi (1997: 289))

To sum, we observe the following facts regarding the landing sites of $\mathrm{A}^{\prime}$ elements in the embedded CP domain.

(21) English

a. A topic phrase moves to Spec, TopP, and TopP can iterate: (16).

b. A relative pronoun as well as a wh-phrase moves to Spec, ForceP: (17) and (18).

(22) Italian

c. A focus phrase moves to Spec, FocP: (17) and (18).

a. A relative pronoun moves to Spec, ForceP: (19).

b. A wh-phrase moves either to Spec, ForceP or to Spec, FocP: (20).

\subsection{Feature-Based Relativized Minimality}

Another widely known constraint on $\mathrm{A}^{\prime}$-movement concerns the blocking effect by the intervening $\mathrm{A}^{\prime}$-element. Rizzi (2004) observes various intervention effects in one clause. For instance, (23a) shows that in Italian the intervening adverb probabilimente 'probably' blocks simple preposing of the adverb rapidamente 'rapidly.' However, as is shown in (23b), probabilimente does not block the focalization of rapidamente.
a. *Rapidamente , I tecnici hanno probabilimente
Rapidly the technicians have probably risolto $t_{\mathrm{i}}$ il problema. resolved the problem

'Rapidly, the technicians have probably resolved the problem.'

(Rizzi (2004: 234))

b. RAPIDAMENTE $\mathrm{i}_{\mathrm{i}}$ I tecnici hanno probabilimente risolto $t_{\mathrm{i}}$ il problema.

'RAPIDLY the technicians have probably resolved the problem.'

(Rizzi (2004: 235))

On the basis of such data, he shows that not all the intervening $\mathrm{A}^{\prime}$ elements block the $\mathrm{A}^{\prime}$-movement of another phrase, and argues that $\mathrm{A}^{\prime}$ - 
elements can be classified into three classes shown in $(24 b-d){ }^{3}$

(24) a. Argumental: person, number, gender, case

b. Quantificational: wh, negation, measure, focus ...

c. Modifier: evaluative, epistemic, negation, frequentative, celerative, measure, manner ...

d. Topic

(Rizzi (2004: 243))

Rizzi (2004: 243) then proposes relativized minimality on the basis of features, which requires that the elements with the feature of the same class exhibit intervention effects. Rizzi assumes that relativized minimality is a representational principle, and holds of chains at LF. The local relation which satisfies relativized minimality is defined as in (25).

(25) Minimal Configuration (Rizzi (2004: 225))

$\mathrm{Y}$ is in a Minimal Configuration with $\mathrm{X}$ iff there is no $\mathrm{Z}$ such that

(i) $\mathrm{Z}$ is of the same structural type as $\mathrm{X}$, and

(ii) $\mathrm{Z}$ intervenes between $\mathrm{X}$ and $\mathrm{Y}$.

Here, the same structural type denotes either heads of the same class or the Spec positions which are licensed by heads with features of the same class in (24). Under this assumption, if two phrases have the feature of the same class, only the closer phrase can be linked to the criterial head, while if they are not, the lower phrase can also be linked to the criterial head. Although Rizzi assumes that relativized minimality is applied to chains at LF, we argue that relativized minimality applies through derivation, prohibiting movements which violate relativized minimality. We call this derivational feature-based relativized minimality (DFRM) and define it as in (26). ${ }^{4}$ Under DFRM, if two phrases are in the same class, the closer of the two is attracted, while if they are not, the lower phrase can move over the higher

\footnotetext{
3 "Measure" denotes amount adverbs such as a lot and little. Here is the other lists of adverbial examples; evaluative adverb: unfortunately, epistemic adverb: probably, celerative adverb: rapidly, suddenly, and frequentative adverb: often. See Cinque (1999) for discussion. Further, it should be noted that negation belongs to both the Quantificational class and the Modifier class, blocking both types of $\mathrm{A}^{\prime}$-movement.

${ }^{4}$ We do not argue against representational models of feature-based relativized minimality. Representational models could equally explain the facts presented here. However, if we assume relativized minimality based on chains at LF, some additional explanation might be necessary to rule in sentences such as (i) $(=(30 \mathrm{a}))$, where the focus element only with great difficulty intervenes the wh-chain formed by what in the world, and it violates feature-based relativized minimality at LF. Thus, we assume derivational feature-based relativized minimality.
}

(i) [What in the world $]_{\mathrm{i}}$ did Lee say that $t_{\mathrm{i}}$ only with great difficulty can she carry $t_{\mathrm{i}}$ ? 
phrase.

(26) Derivational Feature-Based Relativized Minimality $\mathrm{Y}$ can move to $\mathrm{X}$ iff

(i) $\mathrm{Y}$ is in a Minimal Configuration with $\mathrm{X}$, and

(ii) $\mathrm{X}$ and $\mathrm{Y}$ share a feature of the same class.

Given that DFRM applies to $\mathrm{A}^{\prime}$-movement within a clause, it might be plausible to assume that DFRM also regulates $\mathrm{A}^{\prime}$-movement across clauses. Thus, in this paper we explore the latter case and propose that DFRM operates in the articulated CP periphery of an embedded clause, which serves as an intermediate landing site for the long-distance $\mathrm{A}^{\prime}$-movement.

Before examining relevant data, let us consider the intermediate landing sites of $\mathrm{A}^{\prime}$-movements. It has been widely assumed that movements observe locality restrictions; if a phrase moves from the embedded clause to the main $\mathrm{CP}$ domain, it must at least pass through the embedded $\mathrm{CP}$ (Chomsky $(2001,2008))^{5,6}$ Here, a question arises as to which place in the articulated CP domain the phrase makes use of as an intermediate landing site. We could suppose that $\mathrm{A}^{\prime}$-movement to the intermediate site is triggered unselectively (by, for instance, EPP features (Chomsky (2001)) or edge features (Chomsky (2008))), and $\mathrm{A}^{\prime}$-elements move to the same place irrespective of their features. However, such an analysis cannot account for the contrast in (27). Examples in (27) show that embedded $\mathrm{T}^{0}$-to- $\mathrm{C}^{0}$ movement in Belfast English is caused only by wh-movement as in (27a), not by topicalization as in (27b).

(27) Belfast English

a. Who did John hope would he see?

(Henry (1995: 108))

b. *My car, Mary claimed did they steal.

(Rizzi (2006: 126))

Thus, following Rizzi (2006: 110-111), we suppose that movements to

5 Strictly speaking, Chomsky $(2001,2008)$ argues that phrases in the VP of the embedded clause first moves to the embedded $\mathrm{vP}$ domain before moving to the embedded $\mathrm{CP}$ domain. Then, they move to the matrix vP domain and to the matrix CP domain. However, this paper does not refer to movement to the $\mathrm{vP}$ domain except when it is relevant to the discussion (see section 4).

${ }^{6}$ Chomsky (2001) argues that the phase head $\left(\mathrm{C}^{0}\right.$ and $\left.\mathrm{v}^{* 0}\right)$ transfers its complement (domain) to the Interfaces. Although I follow his claim, I do not assume that a splitting head in the left periphery independently transfers its domain to the Interfaces. That is, I assume that $\mathrm{CP}$ and $\mathrm{V}^{*} \mathrm{P}$ are phases, and transfer their domains, but a splitting head within $\mathrm{CP}$ and $\mathrm{v}^{*} \mathrm{P}$ does not make up its own phase. Thus, even if the left periphery splits, the transfer is operated after the highest projection in the $\mathrm{CP}$ or $\mathrm{v}^{*} \mathrm{P}$ domain is completed, and the transfer applies to TP and VP. 
the intermediate places are triggered by purely formal ("pseudo") criterial features, which correspond to criterial features of the criterial heads in the higher $\mathrm{CP}$, and have the same formal features as criterial features which trigger (final) $\mathrm{A}^{\prime}$-movements. Purely formal criterial features are different from criterial features in that the former do not satisfy any criterion, and do not trigger Criterial Freezing effects. Since purely formal criterial features and criterial features share the same features, a purely formal criterial feature resides in the same kind of criterial head as the corresponding criterial feature. Suppose in the case of the long distance wh-movement that the $w h$-feature of $\mathrm{Foc}^{0}$ in the main CP system attracts a wh-phrase in the embedded clause. In this case, Force ${ }^{0}$, a head endowed with a whfeature in the embedded interrogatives, is endowed with a purely formal $w h$-feature and first attracts the $w h$-phrase. Then the matrix $\mathrm{Foc}^{0}$ attracts the wh-phrase to satisfy the Wh Criterion. Similarly, a focus element in an embedded clause is first attracted by the embedded $\mathrm{Foc}^{0}$, which has a purely formal focus feature, and then attracted by the main $\mathrm{Foc}^{0}$. Topicalization out of an embedded clause is also triggered by the embedded Top ${ }^{0}$ with a purely formal topic feature first, and then it is triggered by the Top ${ }^{0}$ in the main CP domain. In what follows, we implicitly assume that such purely formal features induce successive-cyclic $\mathrm{A}^{\prime}$-movement.

Let us turn to the intervention effect. Consider (28), where a focus phrase cannot move to the matrix clause across a wh-phrase which occupies Spec, ForceP in the embedded CP domain. Interestingly, this contrasts with (29) and (30), which show that a wh-phrase can be successfully extracted over a focus phrase. ${ }^{7}$
a. *In no other countries do I wonder what (in the world) you could eat.

b. *In none of these stores do I wonder what (in the world) Mary bought.

\footnotetext{
7 One of the reviewers pointed out the possibility that wh-phrases in (29) can move because it is Discourse (D)-linked. Rizzi (2001) and Endo (2007: 26-32) argue that Dlinked wh-phrases (such as which XP and what) are presupposed in the discourse and act like topics. Under this assumption, it could be argued that wh-phrases in (29) undergo topicalization over focus phrases. However, examples in (30) show that aggressively non D-linked wh-phrases (such as what in the world, what the hell, why, and how) also move over focus phrases. This shows that $w h$-movement over a focus element is possible.
} 
(29) Which books did Lee say that

a. only with great difficulty can she carry?

b. only to Robin will she give?

c. only on the table will she put?

(30) What in the world did Lee say that

(Culicover (1991: 49))

a. only with great difficulty can she carry?

b. only to Robin will she give?

c. only on the table will she put?

First, consider (28a) as an example. In the embedded CP domain, the wh-phrase what (in the world) moves to Spec, ForceP and satisfies the Wh Criterion. The focus phrase in no other countries also moves to Spec, FocP, an intermediate landing site for the movement to the main clause. Then, when the focus phrase is attracted by the $\mathrm{Foc}^{0}$ in the main CP system, a problem arises; under DFRM, the intervening wh-phrase in Spec, ForceP exhibits the intervention effect, because a $w h$-phrase and a focus phrase both belong to the Quantificational class. Therefore, the whphrase blocks focalization to the matrix clause, and the derivation crashes.

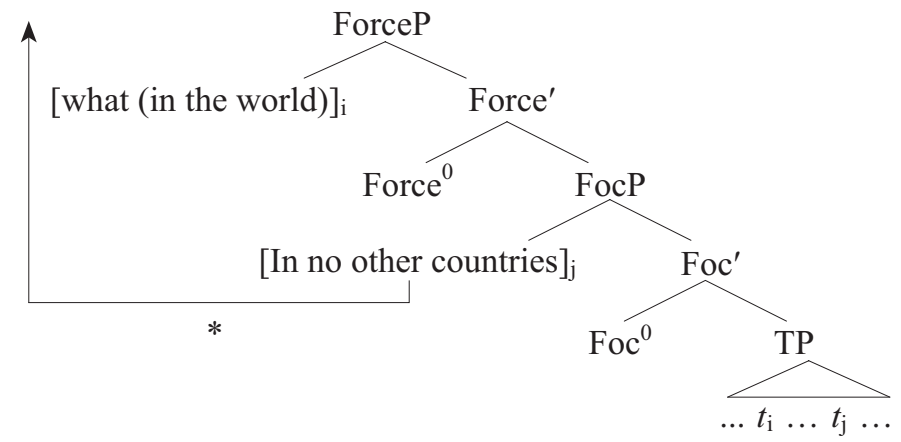

On the contrary, wh-movement over a focus element is possible as in (29) and (30). For instance, the derivational step of (30a) where the embedded $\mathrm{CP}$ domain is introduced is shown in (32). A focus element is attracted by $\mathrm{Foc}^{0}$ and satisfies the Foc Criterion in Spec, FocP. At the same time, a whphrase moves to Spec, ForceP. Then the wh-phrase further moves to the main CP periphery to satisfy the Wh Criterion there. This is a legitimate operation because the focus element is located below the wh-phrase and does not intervene between the $w h$-phrase and the main CP system; whmovement does not violate DFRM. ${ }^{8}$

${ }^{8}$ Here, a problem seems to arise as to why the focus phrase only with great difficulty, 
(32)

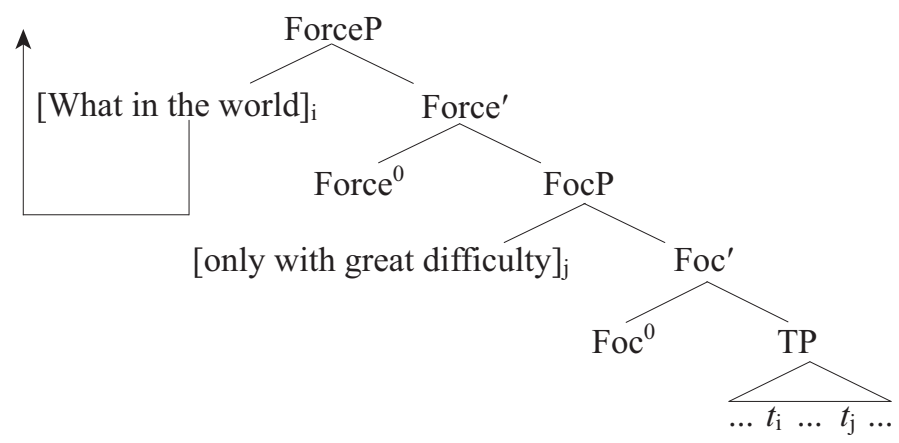

Now note that we do not assume multiple Specs in the CP domain. In the articulated CP periphery, distinct heads with some features may project to satisfy their own criterion. Given that a criterion is a kind of feature checking and is satisfied by one-by-one relation with a phrase with some feature, it is reasonable to assume that a criterion holds between one distinct head and one $\mathrm{A}^{\prime}$-element; it is not the case that two $\mathrm{A}^{\prime}$-elements target the Spec of the same head and satisfy their criteria at the same time. This assumption is supported by the fact that a wh-phrase cannot move over another wh-phrase.

(33) a. *What do you wonder when Aaron would buy?

(Tateishi and Koizumi (2001: 116))

b. *What on earth did you wonder how John had baked?

When trying to move to the main clause, what (on earth) cannot move through Spec, ForceP, as the position is already occupied with when or how. In addition, they cannot move directly from its argumental position to the main $\mathrm{CP}$, since in that case another wh-phrase in the embedded $\mathrm{CP}$ intervenes and causes the intervention effect under DFRM.

The proposal of DFRM also accounts for the absence of intervention effects between a focus element and a topic element as in (34) and (35). For instance, (34a) shows that the focus phrase not even to Terry can move over the topic phrase on my vacation. In the same vein, in (35a) the topic phrase to Terry moves across the focus phrase money.

which resides in Spec, FocP, does not block the movement of what in the world to Spec, ForceP. Chomsky (2008) proposes that movements by the heads in the same phase are operated simultaneously. Under this assumption, it is argued that simultaneous operations do not interfere with each other. 
(34) a. Not even to Terry do I expect that on my vacation I would give my favorite reading material.

b. Under no circumstances do I think that to Terry I would give my favorite reading material.

(Culicover (1996: 456))

(35) a. To Terry, I think that the MONEY, LEE gave. (and I think that the CHECKBOOK, ROBIN gave.)

b. ?The money, I think that to TERRY, LEE gave. (and the CHECKBOOK, ROBIN gave.)

(Culicover (1996: 453))

(36a) is the structure of (34a) and (36b) is the structure of (35a). Given that topics reside in a separate class from other $\mathrm{A}^{\prime}$-elements, it is conceivable that they do not show locality interactions with other types of $\mathrm{A}^{\prime}$ elements. Thus, topics do not show intervention effects on focalization, allowing the lower focus phrases to move to the main clause as in (36a). In the same way, focuses do not block topicalization under DFRM; even if TopP projects below FocP as in (36b), a topic phrase is successfully extracted to the main clause.

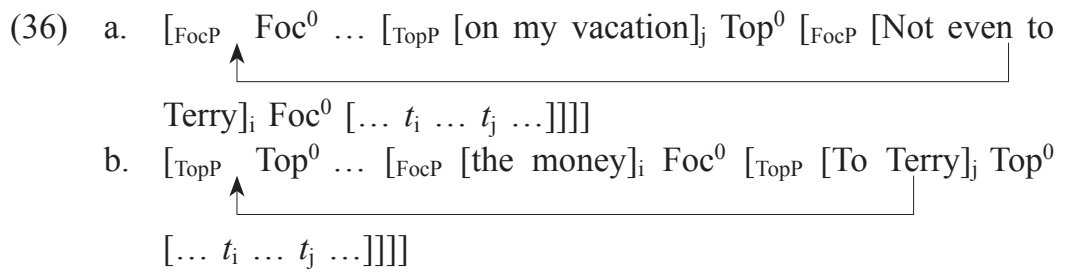

\section{Split $\mathrm{A}^{\prime}$-movement}

In this section we will propose split $\mathrm{A}^{\prime}$-movement and argue that this, in cooperation with the articulated CP system and DFRM, will explain the extractability of elements out of the phrase which has satisfied a criterion.

Chomsky (2008) suggests that $\mathrm{A}^{\prime}$-movement may take place in parallel with A-movement. Consider for example (37), which exhibits no Subject Island Condition effect. At the derivational point where the matrix $\mathrm{CP}$ phase attracts elements, there are two attractors. One is the edge feature of $\mathrm{C}^{0}$ which triggers $\mathrm{A}^{\prime}$-movement to Spec, $\mathrm{CP}$, and the other is the Agree feature of $\mathrm{C}^{0}-\mathrm{T}^{0}$ complex that triggers A-movement to Spec, TP. Chomsky argues that split movement becomes possible if two distinct attracting heads target the different features (A-feature and $\mathrm{A}^{\prime}$-feature) within the same phrase. In this case, the driver of which car in the embedded TP can split, letting of which car move to Spec, CP and the driver move to Spec, TP, si- 
multaneously.

(37) a. Of which car is the driver likely to cause a scandal?

b.<smiles>CC(C)C(C)C(C)C</smiles>

(Chomsky (2008: 153))

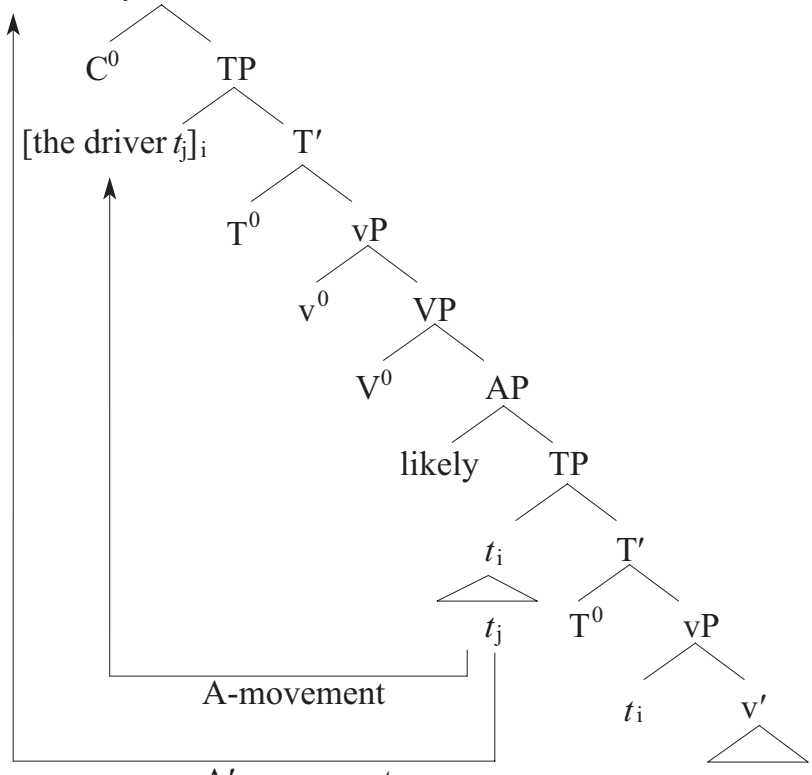

$\mathrm{A}^{\prime}$-movement

We extend this idea and propose that there exists split movement to two distinct $\mathrm{A}^{\prime}$-positions. When two distinct heads in the $\mathrm{CP}$ periphery attract different $\mathrm{A}^{\prime}$-features within one phrase, split $\mathrm{A}^{\prime}$-movement takes place. For instance, suppose that a focus phrase contains a wh-phrase. In such a case, when the phrase moves to the CP domain, the phrase splits and the element with the focus feature moves to Spec, FocP and the element with the whfeature moves to Spec, ForceP in parallel as is shown in (38a). ${ }^{9}$

9 Chomsky also proposes that A-movement and A'-movement of the same phrase can occur in parallel as in (ib). Notice that in this case the same head simultaneously satisfies an Agree feature (which triggers A-movement) and an edge feature (which triggers $\mathrm{A}^{\prime}$-movement).

(i) a. Who saw John?

b. $\quad\left[\mathrm{CP} \mathrm{who}_{\mathrm{i}} \mathrm{C}^{0}\left[\mathrm{TP}\right.\right.$ who $_{\mathrm{i}} \mathrm{T}^{0}\left[{ }_{\mathrm{vP}} t_{\mathrm{i}}\right.$ see John] $\left.]\right]$

(Chomsky (2008: 149))

I will argue, however, that when the same phrase undergoes split movement to two 
(38)

a. split $\mathrm{A}^{\prime}$-movement

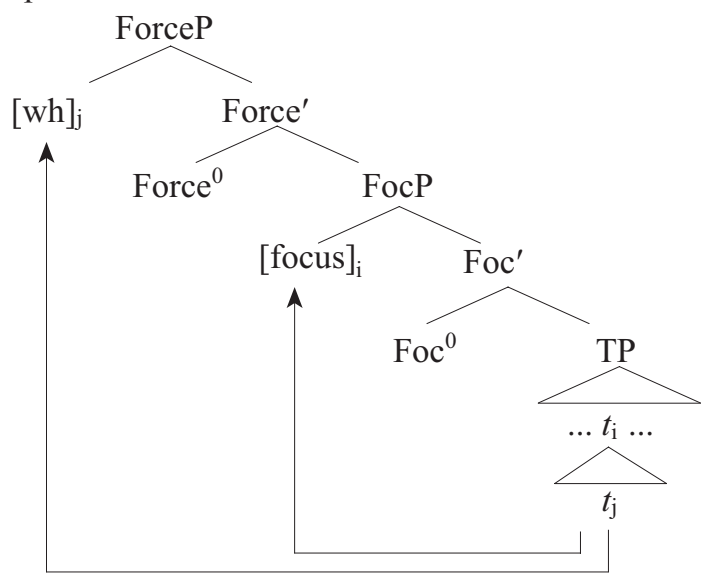

b.

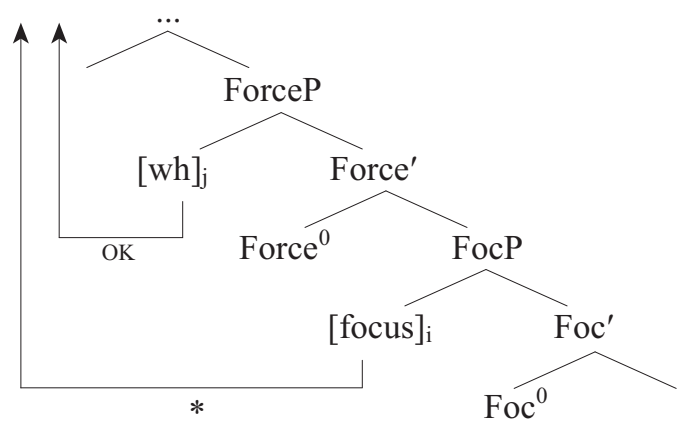

At this point, as in (38b), subsequent wh-movement to the matrix clause is possible if it does not satisfy any criterion in the embedded CP domain. However, the focus element cannot move, since the wh-element acts as an intervener and induces the DFRM effect. Under this assumption, we will clarify the mechanism of extraction phenomena shown in section one.

\subsection{Split $\mathrm{A}^{\prime}$-movement in Italian}

This section demonstrates that facts regarding extraction out of a phrase which has satisfied a criterion in Italian can be explained in terms of split

distinct $\mathrm{A}^{\prime}$-positions, say, to Spec, TopP and Spec, FocP, the sentence results in ungrammaticality. This is derived from the Criterial Freezing effect; a phrase can satisfy one and only one scope-discourse property. The same phrase cannot split in order to satisfy two different criteria. 
$\mathrm{A}^{\prime}$-movement. First consider (39) $(=(3))$, where one phrase involves two $w h$-features. In this case, the legitimate output is that the higher $w h$-phrase quanti libri 'how many books' occupies the embedded CP system, and then the embedded wh-phrase, di quale autore 'by which author,' is further extracted to the main $\mathrm{CP}$ system.

(39) ? [ ${ }_{\mathrm{CP}}[\mathrm{Di} \text { quale autore }]_{\mathrm{j}} \mathrm{C}^{0}\left[\right.$ ti domandi $\left[\mathrm{CP} \text { [quanti libri } t_{\mathrm{j}}\right]_{\mathrm{i}} \mathrm{C}^{0}[$ siano stati censurati $\left.\left.\left.t_{i}\right]\right]\right]$ ?

'By which author do you wonder how many books have been censored?'

Under split $\mathrm{A}^{\prime}$-movement analysis, (39) is generated as in (40). Remember that in Italian there are two landing sites for $w h$-phrases in the embedded $\mathrm{CP}$ domain: Spec, FocP and Spec, ForceP (see (22b)). This makes it possible for each head to attract distinct $w h$-features, splitting the whole $w h$ phrase; quanti libri is attracted to Spec, FocP and di quale autore is attracted to Spec, ForceP in parallel. While the former satisfies the Q Criterion in the embedded FocP and is frozen in place, the latter does not satisfy any criterion and can move to the main CP system. Note that this movement is consistent with DFRM, since there is no intervener between Spec, ForceP in the embedded clause and the matrix $\mathrm{CP}$.

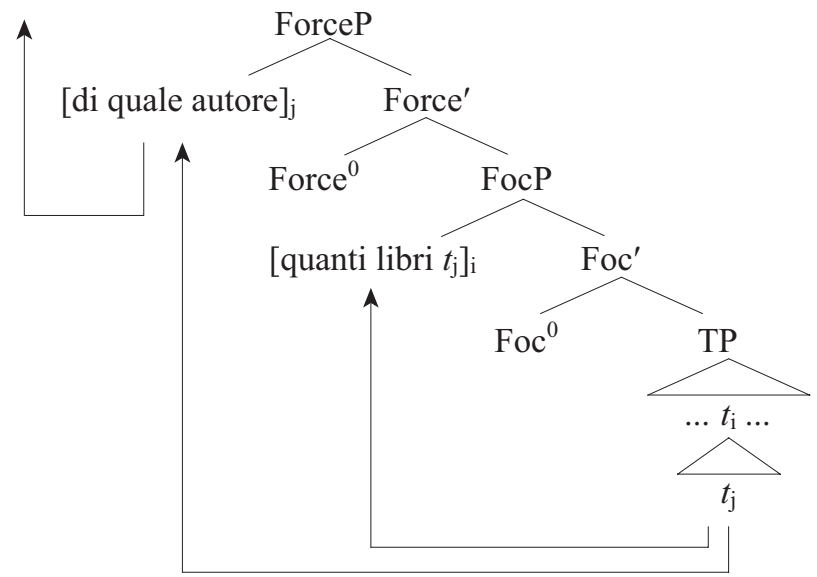

In the same vein, split $\mathrm{A}^{\prime}$-movement accounts for the example (41) $(=(4 \mathrm{~b}))$, where one phrase contains a $w h$-phrase and a relative pronoun.

(41) $\left[\right.$ Gianni, $\left[\right.$ СP $[\text { del quale }]_{\mathrm{j}} \mathrm{C}^{0}\left[\mathrm{mi}\right.$ domando $\left[\mathrm{CP} \text { [quanti libri } t_{\mathrm{j}}\right]_{\mathrm{i}} \mathrm{C}^{0}$ [siano stati censurati $\left.t_{\mathrm{i}}\right]$ ]]]].

'Gianni, by whom I wonder how many books have been censored.' 
(42) $\left[\text { ForceP }_{\text {Force }}^{0} \ldots \text { [ForceP }[\text { del quale }]_{\mathrm{j}} \text { Force }^{0}{ }_{\text {FocP }} \text { [quanti libri } t_{\mathrm{j}}\right]_{\mathrm{i}}$

$$
\left.\left.\operatorname{Foc}^{0}\left[\begin{array}{lll}
\ldots & t_{\mathrm{i}} & \ldots
\end{array}\right]\right]\right]
$$

In Italian, a relative pronoun targets Spec, ForceP and a wh-phrase can target Spec, FocP (or Spec, ForceP) in embedded clauses. When quanti libri del quale 'how many books by whom' is attracted to the embedded $\mathrm{CP}$ system, it splits and quanti libri 'how many books' moves to Spec, FocP, and simultaneously del quale 'by whom' moves to Spec, ForceP. On the one hand, since the subordinate $\mathrm{Foc}^{0}$ requires the Wh Criterion to be satisfied, once the $w h$-phrase moves there, it is frozen in place under Criterial Freezing. On the other hand, the relative pronoun can move to the higher $\mathrm{CP}$ domain to satisfy the Rel Criterion. This movement does not violate DFRM; while the $w h$-phrase and the relative pronoun both have a $w h$-feature and belong to the same class (Quantificational), the latter resides in the higher place than the former and can move further. In the next section we will consider examples in English.

\subsection{Split $\mathrm{A}^{\prime}$-movement in English}

In section one we observed that English exhibits more severe restrictions on the extraction out of a phrase which has satisfied a criterion. For instance, wh-movement out of the wh-phrase that satisfies the Q Criterion is impossible as in (43) and (44) (=(5) and (6)).

(43) *By which author do you wonder how many books have been censored?

(44) a.?? Who do you wonder which picture of Mary bought?

b.?? Who do you wonder which picture of is on sale?

This is reducible to the fact that $w h$-phrases exclusively target Spec, ForceP in the embedded CP domain in English. A wh-phrase with two distinct wh-features cannot undergo split $\mathrm{A}^{\prime}$-movement, since the $\mathrm{CP}$ periphery has only one potential landing site for $w h$-movement.

Also, if the wh-element does not split and moves to the embedded CP periphery as a whole, DFRM exhibits the blocking effect when the subphrase such as by which author or who tries to move to the matrix CP domain. According to DFRM, the extraction of a phrase XP over another phrase YP is impossible if YP c-commands XP and they have the features of the same class. This constraint is applied not only to distinct phrases as in (45a) but also phrases where YP includes XP as in (45b), since in that case the head of YP c-commands XP. 
(45)

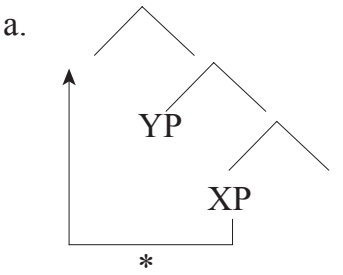

b.

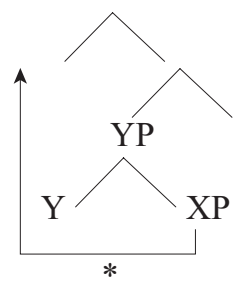

Thus, in cases like (43) and (44), since the head of the higher wh-phrase ccommands the lower wh-phrase, the former blocks the extraction of the latter, and the derivation results in ungrammatical sentences.

This analysis is applicable to the case where a wh-phrase contains a relative pronoun as in $(46)(=(7))$, since a relative pronoun also moves to Spec, ForceP. That is, the phrase cannot split because both the wh-phrase and the relative pronoun target $\mathrm{Spec}$, ForceP in the embedded $\mathrm{CP}$ domain.

(46)?* The man by whom I wonder how many books have been censored called you last night.

Focalization from a wh-moved element is also severely degraded as in (47) $(=(8))$. In the embedded CP domain, a wh-phrase is attracted to Spec, ForceP and a focus phrase is attracted to Spec, FocP. This leads to split $\mathrm{A}^{\prime}$-movement. At this point, the $w h$-phrase satisfies the Q Criterion but the focus phrase does not satisfy the Foc Criterion. Then the matrix Foc ${ }^{0}$ tries to attract a focus phrase to satisfy the Foc Criterion. However, focalization to the matrix CP domain is blocked by DFRM. As the wh-phrase and the focus phrase share the same feature (Quantificational), and the wh-phrase in Spec, ForceP intervenes between the focus element in Spec, FocP and its landing site in the matrix CP domain; the $w h$-phrase expresses the intervention effect. Hence the derivation crashes, yielding ungrammatical sentences (see also Endo (2009) for the argument that the ForceP expresses the intervention effect on the agreement relation between a null operator of a Tag Question clause and a clause which is connected with Tag Question).

a. *Only children did Lee wonder how many pictures of her mother likes.

b.??Of only children did Lee wonder how many pictures her mother likes.

(48) $\left[\text { FocP } \operatorname{Foc}^{0} \ldots \text { [Forcep [how many pictures } t_{\mathrm{j}}\right]_{\mathrm{i}}$ Force $^{0}[$ FocP $[$ Of only $\uparrow$

$*$

children $\left.\left.\left.]_{\mathrm{j}} \operatorname{Foc}^{0}\left[\ldots\left[t_{\mathrm{j}}\right]_{\mathrm{i}} \ldots\right]\right]\right]\right]$

Notice that this approach leads to an expectation that wh-movement out 
of a focus phrase should be possible, since a focus element in Spec, FocP does not intervene between the matrix CP domain and a wh-phrase in Spec, ForceP of the embedded CP domain. Examples in (49) (=(13)) show that this expectation is borne out.

(49) a. Of whom did Lee say that only to mothers will she talk?

b. Of whom did Robin say only with children can he communicate?

(50) $\left[\right.$ FocP Foc $^{0} \ldots$ [ForceP $\left[\text { Of whom } t_{\mathrm{j}}\right]_{\mathrm{i}}$ Force $^{0}[\text { FocP [only to mothers }]_{\mathrm{j}}$ A

$\left.\left.\left.\operatorname{Foc}^{0}\left[\ldots\left[t_{j}\right]_{\mathrm{i}} \ldots\right]\right]\right]\right]$

Also, example (51) $(=(11))$ shows that topicalization out of a topic phrase is possible. In this case, since there are two topic features, TopP in the embedded CP domain iterates and two Top ${ }^{0}$ s independently attract two topic features. ${ }^{10}$ Thus, the topic phrase splits and subparts move to topic positions at the same time. For example, the embedded CP domain of (51b) is shown in (52). In this structure, the higher topic phrase can escape out of the embedded CP without violating DFRM, since there are no intervening topic phrases.

(51) a. ?About vowel harmony, I think that articles, you should read.

b. ?Of John, I think that pictures, Mary likes.

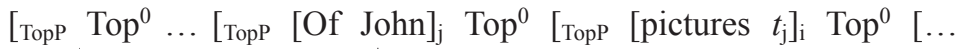

$$
\begin{aligned}
& \left.\left.\left[\begin{array}{ll}
t_{\mathrm{j}} & \ldots \\
\mathrm{i} & \ldots
\end{array}\right]\right]\right]
\end{aligned}
$$

Further, we can extract a focus phrase from a topic phrase as in (53) $(=(12))$. This sentence has two derivational sources. One is shown in (54a), where FocP projects above TopP in the embedded clause. Here, the focus phrase vowel harmony moves to Spec, FocP and the topic phrase articles of moves to Spec, TopP. Then, a focus phrase legitimately moves to the main $\mathrm{CP}$ domain, since there is no intervening $\mathrm{A}^{\prime}$-element. The other derivational source is shown in (54b), where FocP projects below TopP. In this case as well the sentence is grammatical, since a focus phrase can move over a topic phrase even if a topic phrase occupies the higher position than a focus phrase; FocP can be an escape hatch for extraction as in (54b), be-

10 Benincà and Poletto (2004) argue that in Italian topicalization can be classified into two types. They suggest that topicalization which targets TopP higher than FocP expresses old information, while topicalization which targets TopP lower than FocP expresses new information. The latter can be considered as a kind of focalization. We leave the detailed investigation of the nature of the two Tops for the future research. 
cause a topic phrase and a focus phrase do not belong to the same feature class. It is important to note that the lower phrase in the CP domain can move over the higher phrase, if DFRM is respected.

(53) VOWEL HARMONY, I think that articles of, you should read. (54) a.

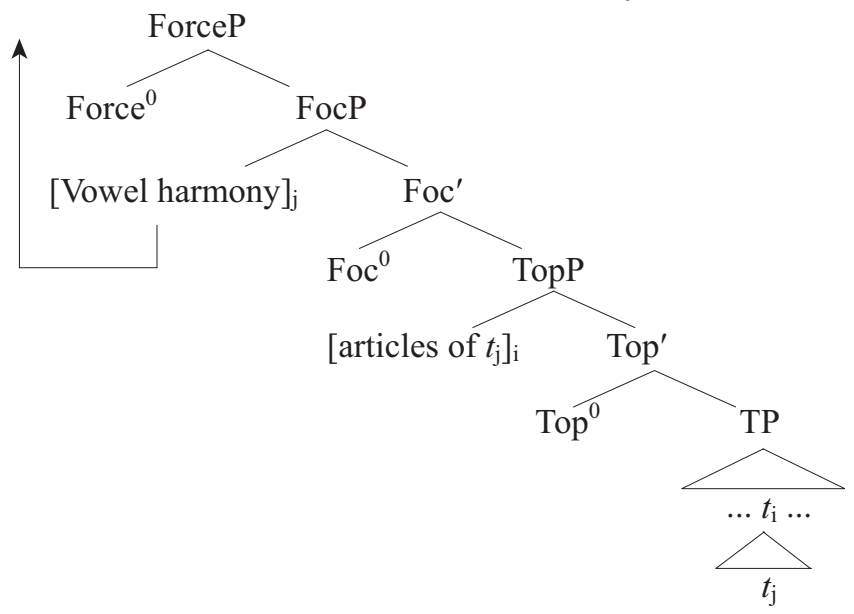

b.

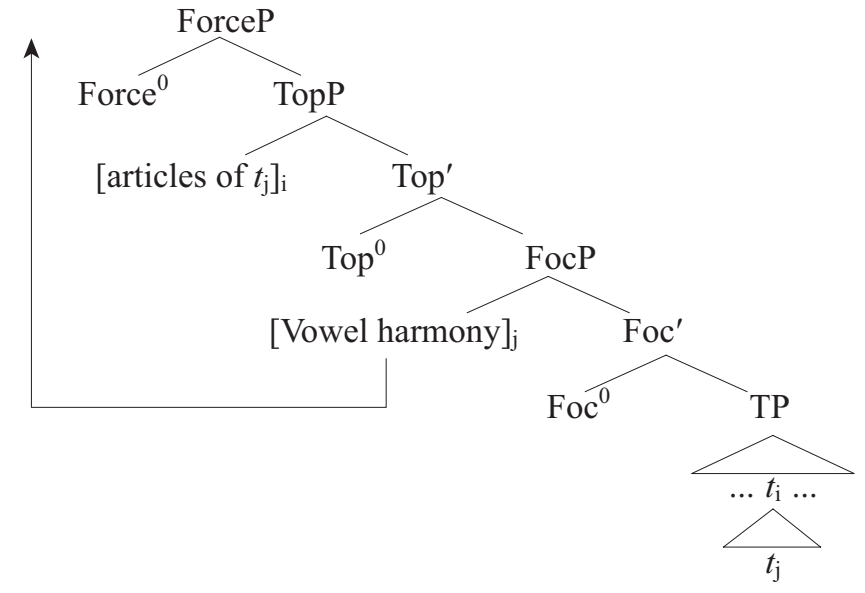

This section has examined extraction out of a phrase which has satisfied a criterion in terms of split $\mathrm{A}^{\prime}$-movement and DFRM in the articulated $\mathrm{CP}$ periphery. The next section will turn to $\mathrm{A}^{\prime}$-movement in there-constructions. We will present an argument that the vP domain also has the hierarchical system and observes Criterial Freezing. 


\section{A'-movement in There-constructions}

This section deals with wh-movement in there-constructions. It has been noted that an associate DP or an element within an associate DP depends on the matrix verb for its extractability; on the one hand, there-constructions with unaccusative verbs (there-unaccusative constructions) do not allow whmovement of an associate DP as in (55a), while they allow the extraction out of an associate DP as in (55b). On the other hand, there-constructions with unergative verbs (there-unergative constructions) ban either type of movement as in $(55 \mathrm{c}, \mathrm{d})$.

(55) a. *How many packages did there arrive in the mail?

Cf. There arrived some packages in the mail.

(Chomsky (2001: 21))

b. Of which artist did there hang a portrait on the wall?

(Nishihara (1999: 394))

Cf. There hung a portrait of some artist on the wall.

c. *Who did there walk into the room?

Cf. There walked a man into the room.

(Hoekstra and Mulder (1990: 34))

d. *Of which community did there walk a member into the room?

Cf. There walked a member of some community into the room.

To explain these phenomena, let us clarify the structure of the vP domain. Under Chomsky's (2008) idea that properties of the CP phase hold of phases generally, we can assume that the $\mathrm{vP}$ periphery also has the articulated structure with hierarchical criterial heads. This assumption is supported by many studies which show the existence of IP internal focus projections and topic projections (Belletti (2001, 2004), Horvath (1986), Tuller (1992), Yanagida (2005)). We further claim that, as in the CP domain, $\mathrm{A}^{\prime}$-elements can satisfy a criterion in the vP periphery, inducing the Criterial Freezing effect. ${ }^{11}$

Now, let us consider one typical function of there-constructions. It has

11 Chomsky $(2001,2008)$ classifies vP phases into $\mathrm{v}^{*} \mathrm{Ps}$ and vPs. The former occur with transitive or experiencer verbs, and the latter occur with passive or unaccusative verbs. He then assumes that only CPs and $\mathrm{v}^{*}$ Ps are endowed with EPP features or edge features, and trigger movements. However, Legate (2003) argues that vPs also trigger movements, showing that the $\mathrm{vP}$ can be a reconstruction site for $\mathrm{A}^{\prime}$-movements. We follow Legate and assume that both $\mathrm{v}^{* 0}$ and $\mathrm{v}^{0}$ can trigger (intermediate) $\mathrm{A}^{\prime}$-movements. 
been noted that there-constructions play a role of introducing new information in the discourse, and associate DPs are endowed with new information. This means that associate DPs are interpreted as a kind of focus (Birner and Ward (1998), Fukuchi (1985)). We argue that the focalization of an associate DP is operated in syntax. That is, an associate DP in a there-construction is attracted by $\mathrm{Foc}^{0}$ and satisfies the Foc Criterion. Since associate DPs follow verbs in there-constructions, this focalization seems to occur in the $\mathrm{vP}$ domain, not in the CP domain. ${ }^{12,13}$ After an associate DP satisfies the Foc Criterion in the vP domain, it shows the Criterial Freezing effect. This Freezing effect causes the restriction on $w h$-movement regarding an associate DP.

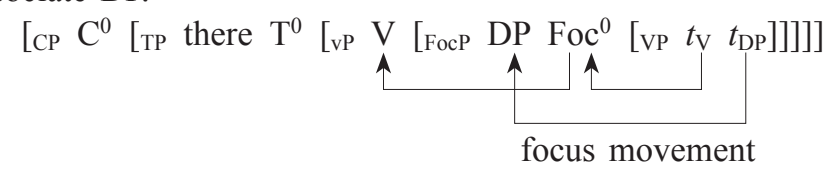

First, consider wh-movement in there-unaccusative constructions. Here, following the unaccusative hypothesis (Perlmutter (1978)), I assume that associate DPs in there-unaccusative constructions are merged in the complement of the verb. Thus, the derivation of (55a) would be like (57). In (57), the associate DP how many packages is first merged in the complement of arrive. Then it undergoes focus movement into the vP domain and satisfies the Foc Criterion. After that, it obeys Criterial Freezing, and can-

12 Verbs move to $v^{0}$ to make $v^{0}-V^{0}$ complex. Chomsky (1995) suggests that this is because $\mathrm{v}^{0}$ is affixal in nature, and needs overt morphological support by $\mathrm{V}^{0} . \mathrm{V}^{0}$ also must satisfy tense and person requirement. This means that $T^{0}$ should attach to $\mathrm{v}^{0}-\mathrm{V}^{0}$ complex. To make the complex head $\mathrm{T}^{0}-\mathrm{v}^{0}-\mathrm{V}^{0}, \mathrm{v}^{0}-\mathrm{V}^{0}$ should be adjacent to $\mathrm{T}^{0}$ because of Head Movement Constraint. Therefore, I argue that $\mathrm{V}^{0}$ moves to the highest head, Force $^{0}$, in the vP periphery. This position is higher than an associate DP which occupies Spec, FocP, yielding the linear order of there-V-DP.

${ }^{13}$ There are two types of foci: identificational focus and information focus (É. Kiss (1998)). The former expresses contrastive focus against some element in the discourse (and can be followed by not $X P$ ), while the latter expresses new information or just an emphasis. Belletti (2001) argues that a focus element in the vP periphery expresses new information. Now, consider (i). Although (ib) is grammatical, it has a different interpretation than (ia). The associate DP in (ia) expresses new information, while the associate DP in (ib) expresses contrastive focus. This shows that associate DPs in thereconstructions usually introduce new information (and they may correspond to postverbal subjects in Italian discussed by Belletti (2001)), while they may have contrastive focus in the proper discourse.

(i) a. There arrived some packages in the mail.

b. There arrived some packages in the mail, not some letters. 
not move further. This is the mechanism of the ban on wh-movement of an associate DP in there-unaccusative constructions.

(57) a. *How many packages did there arrive in the mail?

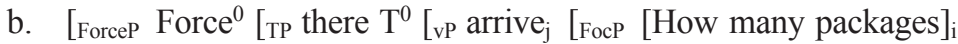

*

$\left.\left.\left.\left.\operatorname{Foc}^{0}\left[\mathrm{vp} t_{\mathrm{j}} t_{\mathrm{i}}\right]\right]\right]\right]\right]$

Now, a problem arises as to why a phrase can be extracted from an associate DP in there-unaccusative constructions. However, this can be explained by split $\mathrm{A}^{\prime}$-movement. The associate DP a portrait of which artist is first merged with hang as its complement. This associate DP, especially the head of the DP, includes a focus feature, and it also includes the whphrase of which artist. Thus, when the vP phase attracts elements, Force ${ }^{0}$ with a purely formal $w h$-feature and $\mathrm{Foc}^{0}$ with a focus feature attract elements simultaneously, leading to split $\mathrm{A}^{\prime}$-movement to the vP periphery. At this point, while the associate DP a portrait is subject to Criterial Freezing and cannot move further, of which artist is already extracted out of the associate DP and can move to the matrix CP domain to satisfy the Q Criterion. Moreover, this wh-movement does not cause DFRM violation, since the focus element, located below the wh-phrase, does not intervene.

(58) a. Of which artist did there hang a portrait on the wall?

b.
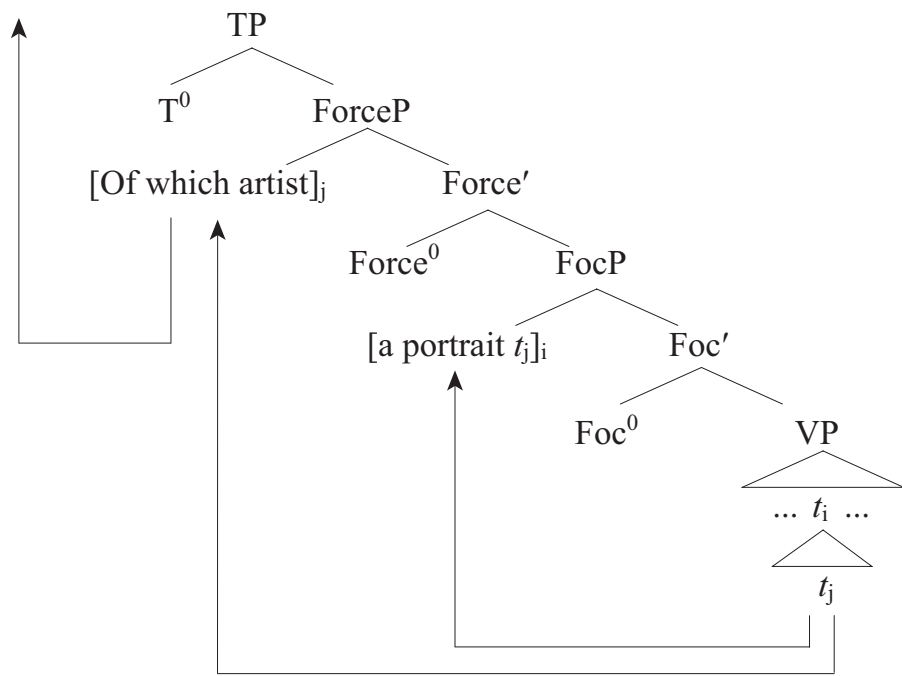

Next, let us examine there-unergative constructions. As examples $(55 \mathrm{c}$, 
d) show, there-unergative constructions do not allow the wh-movement of an associate DP nor the extraction out of an associate DP.

Before considering $w h$-movement, let us clarify the position where an associate DP is merged. It is commonly assumed that subject DPs in unergative sentences are generated in Spec, vP (Hale and Keyser (2002)). Since DPs are given theta roles when they are merged, associate DPs in thereunergative constructions get their theta roles when they are first merged in Spec, vP. Furthermore, since associate DPs in there-constructions possess focus interpretation, associate DPs in there-unergative constructions need to be in Spec, FocP in the vP domain. Under Rizzi's articulated phase system, it is plausible to assume that the vP domain can be amalgamated into one projection when there is no necessity to split. In the case of unergative verbs, the vP domain is amalgamated into one projection, and the externally merged position of an associate DP is also a focus position; an associate DP satisfies both argumental property (theta property) and A'-property (the Foc Criterion) when it is merged.

This assumption explains why there-unergative constructions like (55c) do not allow wh-movement of an associate DP. Since an associate DP satisfies the Foc Criterion when it undergoes external merge, it is immediately frozen in place in the vP domain because of Criterial Freezing.

There-unergative constructions do not allow the extraction of an element from an associate DP, either. At the derivational point of the vP domain, the associate DP a member of which community is merged in Spec, FocP and focalized (being given a theta role at the same time). Then the Criterial Freezing effect restricts the movement of a member. However, if the embedded phrase in the phrase which has satisfied a criterion is exempt from the Criterial Freezing effect, it would seem to move further. This movement, however, is prohibited by DFRM. Recall that the focus element a member and the wh-phrase of which car belong to the same class (Quantificational class). Also, remember that DFRM is at work when one element contains the other element, since in that case the head of the former asymmetrically c-commands the latter. Thus, at the derivational point where the matrix CP domain attracts of which car, the intervening focus element $a$ member prohibits the movement. 
(59)

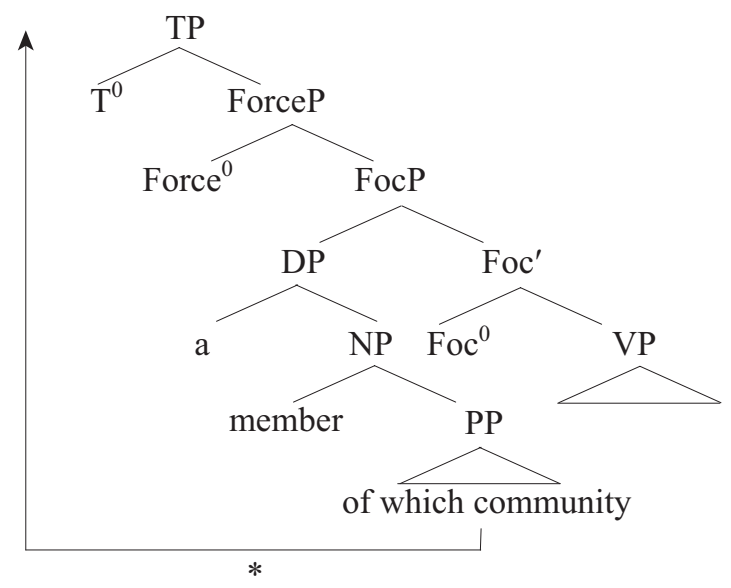

This section presents an argument for split $\mathrm{A}^{\prime}$-movement analysis of thereconstructions. The difference in extractability between there-unaccusative constructions and there-unergative constructions is derived from the difference in externally merged positions of associate DPs. On the one hand, in a there-unaccusative construction an associate DP is merged in the complement of a verb and thus can undergo split $\mathrm{A}^{\prime}$-movement when it moves to Spec, FocP, allowing a $w h$-phrase inside the associate DP to escape. On the other hand, in a there-unergative construction an associate DP is directly merged in Spec, FocP and there is no way to split (to extract a whphrase). This leads to the DFRM effect on the extraction out of an associate DP.

\section{Conclusion}

We have proposed split $\mathrm{A}^{\prime}$-movement, which claims that phrases with different features are attracted to distinct places in the articulated CP domain. Split A'-movement, on a par with DFRM, explains various intervention effects concerning the extraction out of the $\mathrm{A}^{\prime}$-moved phrase. Further, extending the notion of the articulated domain to the vP periphery, we explain wh-movement phenomena concerning associate DPs in there-constructions. This paper contributes to the Minimalist Program in that it gives an account for mechanisms of $\mathrm{A}^{\prime}$-movement, by showing to which place $\mathrm{A}^{\prime}$ elements move and when intervention effects occur. 


\section{REFERENCES}

Belletti, Adriana (2001) “'Inversion' as Focalization,” Subject Inversion in Romance and the Theory of Universal Grammar, ed. by Aafke C. J. Hulk and Jean-Yves Pollock, 60-90, Oxford University Press, Oxford.

Belletti, Adriana (2004) "Aspects of the Low IP Area," The Structure of IP and CP: The Cartography of Syntactic Structures Vol. 2, ed. by Luigi Rizzi, 16-51, Oxford University Press, Oxford.

Benincà, Paola and Cecilia Poletto (2004) "Topic, Focus, and V2: Defining the CP Sublayers," The Structure of CP and IP: The Cartography of Syntactic Structures Vol. 2, ed. by Luigi Rizzi, 52-75, Oxford University Press, Oxford.

Birner, Betty J. and Gregory Ward (1998) Information Status and Noncanonical Word Order in English, John Benjamins, Amsterdam.

Chomsky, Noam (1995) The Minimalist Program, MIT Press, Cambridge, MA.

Chomsky, Noam (2001) "Derivation by Phase," Ken Hale: A Life in Language, ed. by Michael Kenstowicz, 1-52, MIT Press, Cambridge, MA.

Chomsky, Noam (2008) “On Phases," Foundational Issues in Linguistic Theory: Essays in Honor of Jean-Roger Vergnaud, ed. by Robert Freidin, Carlos P. Otero and Maria Luisa Zubizarreta, 133-166, MIT Press, Cambridge, MA.

Cinque, Guglielmo (1999) Adverbs and Functional Heads: A Cross-Linguistic Perspective, Oxford University Press, Oxford.

Culicover, Peter W. (1991) "Polarity, Inversion, and Focus in English," Proceedings of the 8th Eastern States Conference on Linguistics, 46-68.

Culicover, Peter W. (1996) "On Distinguishing A'-Movements," Linguistic Inquiry 27, 445-463.

É. Kiss, Katalin (1998) "Idenificational Focus versus Information Focus," Language $74,245-273$.

Endo, Yoshio (2007) Locality and Information Structure: A Cartographic Approach to Japanese, John Benjamins, Amsterdam.

Endo, Yoshio (2009) "Hanasite to Kikite no Cartography (The Cartography of the Speaker and the Addressee)," Gengo Kenkyu 136, 93-119.

Fukuchi, Hajime (1985) Danwa no Koozoo (The Structure of Discourse), Taishukan, Tokyo.

Haegeman, Liliane (2000) "Negative Preposing, Negative Inversion and the Split CP," Negation and Polarity: Syntactic and Semantic Perspectives, ed. by Laurence R. Horn and Yasuhiko Kato, 21-61, Oxford University Press, Oxford.

Hale, Ken and Samuel J. Keyser (2002) Prolegomenon to a Theory of Argument Structure, MIT Press, Cambridge, MA.

Henry, Alison (1995) Belfast English and Standard English: Dialect Variation and Parameter Setting, Oxford University Press, Oxford.

Hoekstra, Teun and René Mulder (1990) "Unergatives as Copular Verbs: Locational and Existential Predication," The Linguistic Review 7, 1-79.

Horvath, Julia (1986) FOCUS in the Theory of Grammar and the Syntax of Hungarian, Foris, Dordrecht. 
Lasnik, Howard and Mamoru Saito (1992) Move $\alpha$ : Conditions on Its Application and Output, MIT Press, Cambridge, MA.

Legate, Julie A. (2003) "Some Interface Properties of the Phase," Linguistic Inquiry 34, 506-516.

Nishihara, Toshiaki (1999) "On Locative Inversion and There-Construction," English Linguistics 16, 381-404.

Perlmutter, David M. (1978) "Impersonal Passives and the Unaccusative Hypothesis," BLS 4, 157-189.

Rizzi, Luigi (1996) "Residual Verb Second and the Wh-Criterion," Parameters and Functional Heads: Essays in Comparative Syntax, ed. by Adriana Belletti and Luigi Rizzi, 63-90, Oxford University Press, Oxford.

Rizzi, Luigi (1997) "The Fine Structure of the Left Periphery," Elements of Grammar: Handbook of Generative Syntax, ed. by Liliane Haegeman, 281-337, Kluwer, Dordrecht.

Rizzi, Luigi (2001) "Reconstruction, Weak Island Sensitivity, and Agreement," Semantic Interfaces: Reference, Anaphora and Aspect, ed. by Carlo Cecchetto, Gennaro Chierchia and Maria Teresa Guasti, 145-176, CSLI Publications, Stanford.

Rizzi, Luigi (2004) "Locality and Left Periphery," Structures and Beyond: The Cartography of Syntactic Structures Vol. 3, ed. by Adriana Belletti, 223-252, Oxford University Press, Oxford.

Rizzi, Luigi (2006) "On the Form of Chains: Criterial Positions and ECP Effects," Wh-Movement: Moving On, ed. by Lisa Cheng and Norbert Corver, 97-133, MIT Press, Cambridge, MA.

Rochemont, Michael S. and Peter W. Culicover (1990) English Focus Constructions and the Theory of Grammar, Cambridge University Press, Cambridge.

Tateishi, Koichi and Masatoshi Koizumi (2001) Bun no Koozoo (The Structure of Sentences), Kenkyusha, Tokyo.

Tuller, Laurice (1992) "The Syntax of Postverbal Focus Constructions in Chadic," Natural Language and Linguistic Theory 10, 303-334.

Yanagida, Yuko (2005) The Syntax of FOCUS and WH- Questions in Japanese: A Cross-Linguistic Perspective, Hituzi Syobo, Tokyo.

[received April 1 2010, revised and accepted July 16 2010]

Department of Language and Literature

Kyushu University

6-10-1 Hakozaki, Higashi-ku, Fukuoka-shi

Fukuoka 812-8581

e-mail: matyatyatyako@gmail.com 